\title{
O naturalismo sob o olhar modernista: Candido e a crítica a Aluísio Azevedo
}

\author{
Antonio Carlos Santos*
}

\begin{abstract}
Resumo
Repensar a crítica modernista ao naturalismo brasileiro, especificamente a de Antonio Candido a Aluízio Azevedo, a partir das reflexões de Jacques Rancière, segundo o qual o realismo não é mímesis e sim o momento em que se dá o pulo para fora da representação, e da ideia de glosa que desmancha a relação hierárquica entre metrópole e periferia para instaurar uma relação de forças no campo intelectual entre, especificamente, produções do naturalismo brasileiro e produções do naturalismo francês (Aluízio Azevedo e Émile Zola).
\end{abstract}

\section{Palavras-chave}

Literatura. Naturalismo. Crítica.

Em um ensaio em que faz um panorama das artes plásticas do século XIX, Alexandre Eulálio (1992) faz menção, en passant, a Belmiro de Almeida censurando no pintor que havia se formado na Academia Imperial de Belas-Artes uma relação, digamos, interesseira com o "público que compra". Assinala no artista uma posição dúplice: por um lado, "experimenta técnicas divisionistas desde 1890", por outro, "leva avante, para uso do público que compra, glosas diversas da obra de um Gervex". Eulálio não fala em cópia e sim em glosa, palavra usada pelos poetas para dar conta de uma composição que desenvolve um mote, geralmente mantendo o número de versos do poema fonte e terminando cada estrofe com um verso do mote. A palavra indica ainda anotação entre as linhas ou na margem de um texto para explicar o sentido de uma expressão ou esclarecer uma passagem obscura; nota explicativa, comentário, ganhando, em seguida, também um caráter negativo (parecer contrário, censura, desaprovação). Etimologicamente, vem de $\gamma \lambda \omega \sigma \sigma \alpha$, língua, ponta, extremidade. A glosa de Belmiro, portanto, seria um comentário ao quadro de Gervex.

\footnotetext{
* Docente do Programa de Pós-Graduação em Ciências da Linguagem da Universidade do Sul de Santa Catarina (UNISUL). Doutor em Literatura pela Universidade Federal de Santa Catarina (UFSC). E-mail: caco1955@hotmail.com.
} 
Poderíamos pensar que $O$ cortiço, romance de Aluísio Azevedo, de 1890, também é uma glosa aos romances de Émile Zola, especificamente a L'Assommoir, como reconhece Antonio Candido fazendo disto o ponto de partida para o texto "De cortiço a cortiço", publicado em 1991 na revista Novos Estudos (Cebrap), mas escrito em 1973. A análise se insere, aliás, no interesse de Candido pelo naturalismo e vinha precedida de um texto sobre o romance de Zola, "Degradação do espaço", publicado pela Revista de Letras da Faculdade de Filosofia de Assis, e posteriormente reunido na primeira parte de $O$ discurso e a cidade (1993) juntamente com o já clássico "Dialética da malandragem", de 1970, e "O mundo-provérbio", de 1972, uma leitura de $I$ malavoglia (1881), de Giovanni Verga. O problema que detona a análise de Candido é o da "filiação de textos e de fidelidade aos contextos" ou seja o da relação entre os romances de Zola e de Aluísio Azevedo, sendo o deste, por um lado, "texto segundo" por ser inspirado em L'Assommoir, mas, por outro, "texto primeiro na medida em que filtra o meio", apresentando assim um caráter ambíguo, pois opera na interação do "impacto dos textos feitos nos países centrais" com a "solicitação imperiosa da realidade natural e social imediata".

Esse mesmo problema poderia ser traçado na polêmica entre o discípulo de Candido, Roberto Schwarz, principalmente em "As idéias fora do lugar" (1973) e "Nacional por subtração" (1986), e Silviano Santiago, em "O entre-lugar do discurso latino-americano" (escrito em francês e lido em março de 1971 na Universidade de Montréal), "Eça, autor de madame Bovary" (escrito em inglês e lido em 1970 na Universidade de Indiana), "Apesar de dependente, universal" (1980) e "Por que e para que viaja o europeu" (1984).

Vamos nos concentrar, no entanto, no texto de Candido. A primeira coisa a notar é a diferença de tratamento dada pelo autor ao naturalismo em Formação da Literatura Brasileira (1959) e no texto de 1973. No terceiro capítulo do segundo volume da Formação, Candido condena o naturalismo brasileiro por ter "renegado o trabalho admirável de Alencar [...] para inspirar-se em Zola e Eça de Queirós. A conseqüência foi que nossos naturalistas [...] caíram nos mesmos erros dos românticos (sobretudo Aluísio Azevedo) sem aproveitar a sua lição". Quatorze anos depois, a leitura que faz do mesmo Aluísio Azevedo já é outra. Ao destacar o caráter ambíguo do romance, sendo ao mesmo tempo texto segundo (cópia) e texto primeiro, Candido o julga "bem realizado", embora continue condenando o restante da obra do escritor maranhense como "geralmente medíocre", na medida em que "filtra o meio", mesmo vendo este meio "com lentes tomadas de empréstimo". Candido abre seu ensaio apresentando dois extremos de visão em relação à obra literária: de um lado a idéia de que um texto é constituído a partir de outros textos, "um objeto manufaturado com arbítrio soberano", de outro, a de que é reduplicação da realidade, ou seja as duas pontas da guerra teórica de então, estruturalistas e marxistas. Embora reconheça na primeira mais produtividade para a análise literária, introduz uma terceira via, aliás já apresentada no ensaio que abre o livro, "Dialética da malandragem", que consistiria em "rastrear na obra o mundo como material, para surpreender no processo vivo da montagem a singularidade da forma segundo a qual é transformado no mundo novo, que dá a ilusão de bastar-se a si mesmo". 
Reapresentado o método que será retomado por Schwarz nas análises de Machado de Assis, Candido expõe em seguida a filiação de $O$ cortiço a L'Assommoir, elencando as muitas semelhanças: a vida do trabalhador pobre em um cortiço, as lavadeiras e seu cotidiano, uma festa dionisíaca com conseqüências importantes para o desenrolar dos dois enredos, o policial na figura da lei, também morador do cortiço, etc. Em seguida, explica a diferença entre os dois romances: enquanto o de Zola trabalha mais focado na queda de Gervaise e de sua família no bairro operário, o de Aluísio Azevedo é tematicamente mais variado, pois sendo na sociedade francesa a diferenciação mais acentuada, era preciso mais especialização, enquanto "nos países pouco desenvolvidos como o Brasil" isso talvez resultasse em diluição, razão pela qual Aluísio lança mão não apenas de L'Assommoir, mas também de Nana, de La Joie de Vivre, La Curée e Pot-Bouille. Assim, coloca ao lado do cortiço, a mansão de um rico comerciante, polarizando a narrativa entre os pobres moradores explorados, o capitalista português explorador que trabalha cegamente para acumular, João Romão, o dono do cortiço, e o português rico, Miranda, que mora no sobrado ao lado e aspira a um título de nobreza.

A análise se dirige então para uma nova ambigüidade: a "curiosa mistura de lucidez e obnubilação" demonstrada pelo narrador ao se colocar na posição do brasileiro branco e livre, ou seja, daquele que por um lado tem como antagonista o português que vem ao Brasil para enriquecer pelo trabalho, mas que não quer ser confundido com o "homem do trabalho bruto", o escravo. Desta forma, a violência expressa no romance se dá no jogo entre o português rico, o português que está enriquecendo com a exploração do cortiço e do comércio, o nativo branco que despreza a ambos, mas deseja tomar seu lugar de senhor, e o negro e a "arraia miúda do cortiço", relação essa permeada pela posição ambígua do narrador sujeito às contradições da época. Em seguida, expõe a lógica de uma dialética do espontâneo e do dirigido para entender a transformação do cortiço horizontal aparentemente regido por uma ordem natural, embora contenha em germe o planejamento racional do capitalista, e o novo cortiço, regido por uma ordem mais rígida, que aparece no mesmo momento em que seu dono, João Romão, constrói também um sobrado, símbolo de sua riqueza, e se iguala ao vizinho rico, o português Miranda, que passará de inimigo a aliado no momento em que, já para o final, João Romão se casa com a filha de Miranda abandonando Bertoleza, a ex-escrava que Ihe havia ajudado a chegar onde chegou.

Candido então passa a ler o romance de Aluísio Azevedo como alegórico, como uma alegoria do Brasil, colocando em dúvida se seria "um romance naturalista verdadeiro", pois este "não deseja ir além da realidade observável". Aqui, vale voltar a uma cansativa repetição, que nos faz ficar atentos pois é este o sinal do sintoma, de que o naturalismo teria uma relação não mediada com o "real". Na abertura do ensaio, é assim que Candido o define: "E para o naturalismo a obra era essencialmente uma transposição direta da realidade, como se o escritor conseguisse ficar diante dela na situação de puro sujeito em face do objeto puro, registrando (teoricamente, sem interferência de outro texto) as noções e impressões que iriam constituir o seu próprio texto". (CANDIDO, 1991, p. 123) Ora, não é difícil problematizar essa noção do naturalismo com os textos que Zola escreveu para revistas e jornais, a partir de 
agosto de 1879, e publicados em livro em 1880 com o título Le roman experimental: aí o autor de Nana elabora a diferença entre observação, procedimento dos realistas, e experimentação, dos naturalistas. Diz Zola que a idéia de experiência, tomada das ciências duras, traz com ela a idéia de modificação e cita Claude Bernard para distinguir entre observação e experimentação: "Damos o nome de observador àquele que aplica os procedimentos de investigação simples ou complexos aos estudos dos fenômenos que ele não faz variar e que ele recolhe, conseqüentemente, tais como a natureza os oferece; dá-se o nome de experimentador àquele que emprega os procedimentos de investigação simples ou complexos para fazer variar ou modificar, a partir de um determinado objetivo, os fenômenos naturais e os fazer aparecer em circunstâncias ou em condições nas quais a natureza não os apresentava". (2006, p. 51)

Apesar da insistência na verdade, garantida pelo método científico, e da luta contra os "retóricos", os idealistas, os românticos, Zola tem ainda uma teoria da linguagem (théorie de l'écran), exposta ao amigo Valabrègue em uma carta de 18 de agosto de 1864, que demonstra uma clara noção da inevitável interferência do sujeito em seu objeto. Segundo essa teoria, a percepção de um objeto nunca se dá diretamente, mas através de uma tela (écran), de uma "personalidade", de um "temperamento": "A imagem que se produz nessa tela [...] é a reprodução das coisas e das pessoas colocadas à distância, e esta reprodução, que não poderia ser fiel, mudará tantas vezes quantas uma nova tela vier se interpor entre nosso olho e a criação. [...] A realidade exata é, portanto, impossível na obra de arte". (2006, p. 413) Zola depois discorre sobre os vários tipos de tela: a clássica, a romântica e a realista escolhendo, evidentemente, a realista como a "mais real", como aquela que apresenta as imagens "mais fiéis que uma tela pode apresentar". Claro que Zola também oscila e em "O senso de real" (1878) define essa qualidade mestra do romancista como "sentir a natureza e representá-la tal como ela é". Mas se alguma coisa define o realismo ou o naturalismo é sua contraposição ao romantismo, ou seja, assim como os fonemas de Saussure, sua definição não pode ser essencial, substancial, mas contrastiva, só funciona como oposição a um outro contra o qual se quer estabelecer.

A questão da alegoria entra então no texto de Candido também sob o signo da estranheza, já que não deveria estar ali pois "não ocorre no Naturalismo em geral", embora apareça "sem dúvida nos (romances) de Zola". É uma estranha "espécie de realismo alegórico segundo o qual as descrições da vida quotidiana contêm implicitamente um outro plano de significado". Embora não concorde com Lukács, para quem o pecado do naturalismo foi não "espelhar" corretamente a realidade, Candido parece às vezes proceder de modo semelhante: dada uma certa noção de naturalismo, tenta fazer com que o romance de Aluísio Azevedo corresponda a ela. Mas embora não devesse estar ali, é exatamente ela que traduz a força do livro. À ação do meio cortiço somado ao meio natureza brasileira corresponde uma outra força, que atua de dentro pra fora, qual seja, a da exploração do português, e aqui Candido acha finalmente aquilo que procurava, ou seja, aquilo que já estava exposto em "Dialética da malandragem": a similaridade entre o movimento social e o movimento da narrativa. Com isso praticamente se fecha o círculo da análise. Antes, porém, o autor da Formação faz questão de ressaltar mais dois aspectos: o das metáforas animais, e aí, 
mais uma vez, detecta um "avanço curioso em relação aos modelos europeus". Tendo o cuidado de deixar claro que não deseja julgar Aluísio Azevedo, Candido aponta para uma quebra da pretensa objetividade científica quando a visão fisiológica é transformada em "lubricidade e até obscenidade". O segundo aspecto é o caso de Pombinha, seduzida pela prostituta francesa Léonie. Aqui é curioso ver como o julgamento de Candido pode se virar contra ele. Se antes havia feito questão de lembrar o racismo de Aluísio Azevedo, que ao se referir à Bertoleza e à Rita Baiana afirma que ambas buscavam um "homem superior" no "macho europeu", agora, no caso de Pombinha, é sua vez de escorregar em uma casca de banana de sua geração. Ao comparar Pombinha com a heroína de Zola em La Joie de Vivre, onde o sangue menstrual também faz sua aparição para indicar a passagem para a vida madura da mulher, Candido afirma que ao contrário de Pauline Quenu, Pombinha é "enfermiça" e nervosa e complementa: "[...] e o toque de anormalidade se acentua pela interferência do safismo, que Aluísio adota como solução, fazendo uma cruza meio perversa entre La Joie de Vivre e Nana". Ao descrever a iniciação de Pombinha por Léonie, Candido qualifica a relação homossexual como "ato desnatural" para, na página seguinte, ao ressaltar o traço original de $O$ cortiço, atribuir ao "safismo" - que curiosamente o dicionário Houaiss registra como sendo também "atributo de quem é esperto, safo" - seu caráter "degradante, abaixo da realidade natural".

Valeria ainda trabalhar com a questão da natureza brasileira, esse personagem responsável, em parte, pela sedução de Jerônimo, pela vinda da menstruação de Pombinha, esse personagem, como diz Candido, "que escalda o sangue, dissolve os costumes, desencaminha os portugueses honrados", essa natureza que funciona como força perigosa e que faz o crítico ligar $O$ cortiço a Iracema de José de Alencar. E ler essa natureza não do ponto de vista pessimista do ressentido e sim, por exemplo, do de Lezama Lima para quem "lo único que crea cultura es el paisaje y ese lo tenemos de maestra monstruosidad". (1993, p. 63) E a partir daí inverter a lógica de que o vencedor é o português canalha que acumula capital e não aquele que se deixa seduzir pela terra, por Rita Baiana e pelo café, ou seja, ler a lógica de uma certa resistência ao capitalismo, ao trabalho tal como o exige a máquina do capital. Desta forma, articularíamos Iracema e $O$ cortiço a Catatau, de Paulo Leminski, onde a natureza dos trópicos é responsável pela desmontagem da lógica de Renatus Cartesius, pelo delírio do europeu cuja taxionomia não dá conta de uma outra paisagem, de uma paisagem do outro.

Meu objetivo não é também, poderia dizer mimetizando Candido, julgá-lo, mas ressaltar sua "curiosa mistura de lucidez e obnubilação", pois o mais interessante em seu texto é exatamente esse movimento de captar a ambigüidade na narrativa de Aluísio Azevedo, assim como na posição do intelectual brasileiro do século XIX, e a complexidade na relação entre o texto "primeiro" e o "segundo", tentar escapar à condenação e ao incômodo que o naturalismo ainda produz na crítica brasileira, sempre muito ciosa de apontar os preconceitos e o racismo e de insistir em uma visão do realismo e do naturalismo como miméticos, qualificando-os, como diz Roland Barthes em "O efeito de real", de regressivo em relação à "grande causa da modernidade" que seria a "desintegração do signo" para colocar em questão "a estética secular da representação" (1988, p. 165) E mais, de insistir em uma relação 
de subordinação entre os textos do naturalismo brasileiro e os de Zola, remoendo a idéia da dependência de um ponto de vista ressentido. O esforço de Candido, ambíguo como o romance de Aluísio Azevedo, se torna produtivo na medida em que tenta escapar dessa relação, o que, por exemplo, não acontece nas análises de Roberto Schwarz para quem as idéias estão sempre fora do lugar, embora o autor da Formação ache em $O$ cortiço aquilo que queria de antemão encontrar: a similaridade entre o movimento social e o movimento da narrativa.

A noção de glosa, detonada por Alexandre Eulálio na leitura de Belmiro de Almeida, nos permite estabelecer uma relação que, diga-se de passagem, é bastante comum no meio dos pintores e dos poetas, qual seja, a de glosar os temas clássicos numa reverência antropofágica à valentia dos mestres. Na nota à segunda edição de Nas malhas da letra, Silviano Santiago relembra seus livros anteriores para detectar em Uma literatura nos trópicos uma "certa euforia narcisista" que perdeu o vigor e praticamente se apagou com o século. (2002, p. 9) Diz ele que o livro que traz os ensaios-chave para o debate com Schwarz, "O entre-lugar do discurso latinoamericano" e "Eça, autor de madame Bovary", pareceria datado "se o novo milênio não nos tivesse trazido questões que ali foram expostas e discutidas". Ou seja, se a euforia narcisista arrefeceu, os problemas da "dependência cultural" continuam e parecem exigir um outro enfoque: nem a condenação das idéias fora do lugar, nem a euforia narcisista. Feitas as contas com o modernismo esgotado, está na hora de rever o naturalismo e o realismo, pensando com Jacques Rancière que o realismo não é mímesis, não é a valorização da semelhança mas sim "a destruição dos limites dentro dos quais ela funcionava" (2005, p. 35) ou com Georg Simmel que o naturalismo "não provém de um interesse pela natureza e sim pela arte" e consiste em uma aproximação aos objetos - a focalização fragmentada ou próxima a que Rancière se refere -, enquanto no simbolismo o que está em jogo é o "encanto da distância" (der Reiz der Distanz). Este é um trabalho a ser feito.

\section{Referências}

CANDIDO, Antonio. Formação da Literatura Brasileira: momentos decisivos. 5. ed. Belo Horizonte, Itatiaia; São Paulo, Ed. da USP, 1975.

O discurso e a cidade. São Paulo: Duas Cidades, 1993

EULÁLIO, Alexandre. "O século XIX - Tradição e ruptura (Panorama das artes plásticas)" in Escritos. Org. Berta Waldman e Luiz Dantas. Campinas, Ed. da Unicamp; São Paulo, Ed. da UNESP, 1992.

LIMA, José Lezama. La expresión americana. Edición de Irlemar Chiampi com El texto establecido. México: Fondo de Cultura Econômica, 1993

SANTIAGO, Silviano. Uma literatura nos trópicos. Ensaios sobre dependência cultural. $2^{\text {a }}$ Ed. Rio de Janeiro: Rocco, 2000.

ZOLA, Émile. Le Roman experimental. Présentation par François-Marie Mourad. Paris: GF Flammarion, 2006. 


\section{Title}

Naturalism under the Modernist Gaze: Candido and the Criticism at Aluizio Azevedo

\section{Abstract}

The present essay discusses the modernist criticism on Brazilian naturalism, specifically that by Antonio Candido and Aluízio Azevedo, based on the propositions by Jacques Rancière, who claims that realism is not mimesis, but the moment when art abandons representation. Rancière's idea of gloss, which unmakes the hierarchical relation between the metropolis and the periphery in order to install a power relation in the intellectual field is used for a discussion on the naturalism of the French writer Èmile Zola and the Brazilian writer Aluízio Azevedo.

\section{Keywords}

Literature. Naturalism. Criticism.

Recebido em 10.08.2011. Aprovado em 25.10.2011. 
